\title{
Transactivation of epidermal growth factor receptor through platelet-activating factor/receptor in ovarian cancer cells
}

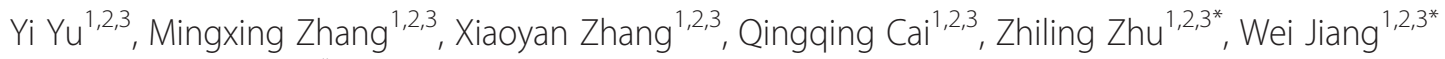
and Congjian $\mathrm{Xu}^{1,2,3,4^{*}}$

\begin{abstract}
Background: We previously identified platelet-activating factor receptor (PAFR) as being overexpressed in ovarian cancer and found that its ligand PAF evoked EGFR phosphorylation using the phospho-antibody microarray. Epidermal growth factor receptor (EGFR) are also overexpressed in ovarian cancer and contribute to the growth of ovarian cancer cells. Here, we investigated the mechanisms of crosstalk between PAFR and EGFR signaling in ovarian cancer cells to further determine whether the interaction between PAFR and EGFR synergistic contribute to the progression of ovarian cancer.
\end{abstract}

Methods: Expression and localization of PAFR in several ovarian cancer cell lines were assessed by Western blot, realtime-PCR and immunofluorescence. The ovarian cancer cells were stimulated with PAF or PAF and in some experiments also pharmacological inhibitors. Phosphorylation of proteins in signaling pathways were measured by Western blot. HB-EGF concentrations of the supernatant from stimulated ovarian cancer cells were measured by enzyme-linked immunosorbent assay.

Results: Our data show that PAF increases EGFR phosphorylation through PAFR in a time- and dose- dependent manner in SKOV-3 ovarian cancer cells. This transactivation is dependent on phospholipase C- $\beta$ and intracellular calcium signaling. This pathway is also Src tyrosine kinase- and metalloproteinase- dependent. PAF triggers EGFR activation through the increased heparin-binding EGF-like growth factor (HB-EGF) release in metalloprotease-dependent manner. Several studies involving EGFR transactivation through G-protein coupled receptor (GPCR) have demonstrated EGFR-dependent increase in ERK1/2 phosphorylation. Yet in SKOV-3 cells, PAF treatment also increases ERK1/2 phosphorylation in a EGFR-independent manner.

Conclusions: The results suggest that in SKOV-3 ovarian cancer cells, PAF transactivates EGFR and downstream ERK pathways, thus diversifying the GPCR-mediated signal. The crosstalk between PAFR and EGFR suggests a potentially important signaling linkage between inflammatory and growth factor signaling in ovarian cancer cells.

Keywords: Platelet-activating factor receptor, Epidermal growth factor receptor, Ovarian cancer cells, Transactivation

\footnotetext{
*Correspondence: zhilingzhu888@126.com; jw52317@126.com;

xucongjian@gmail.com

'Obstetrics and Gynecology Hospital, Fudan University, No.419 Fang-Xie

Road, Shanghai 200011, People's Republic of China

${ }^{4}$ Institute of Biomedical Sciences, Fudan University, Shanghai 200032,

No.138 Yi-Xueyuan Road, Shanghai 200032, People's Republic of China

Full list of author information is available at the end of the article
}

\section{Biomed Central}

(c) 2014 Yu et al.; licensee BioMed Central Ltd. This is an Open Access article distributed under the terms of the Creative Commons Attribution License (http://creativecommons.org/licenses/by/4.0), which permits unrestricted use, distribution, and reproduction in any medium, provided the original work is properly credited. The Creative Commons Public Domain Dedication waiver (http://creativecommons.org/publicdomain/zero/1.0/) applies to the data made available in this article, unless otherwise stated. 


\section{Background}

Platelet-activating factor (PAF), prostaglandins (PGs), and lysophosphatidic acid (LPA) are the three major phospholipid mediators implicated in many different biological pathways in inflammatory diseases and cancers [1-4]. Lipid mediators play a critical role in cancer initiation and progression. PAF induces diverse cellular effects through its specific receptor, PAFR, which belongs to the G-protein coupled receptor (GPCR) family and transduces cell signals via G-proteins and associated protein phosphorylation cascades [5-7]. Many types of cells, when challenged with PAF, showed the activation of tyrosine kinase [8] and protein phosphorylation [9-11].

The epidermal growth factor (EGF) receptor (EGFR) is upregulated in ovarian cancer, and increased expression is associated with reduced survival rate [12-15]. EGFR is emerging as an important therapeutic target for several epithelial tumors, including ovarian cancer. Yet, recent clinical trials targeting EGFR using cetuximab [16-18], matuzumab [19,20], gefitinib [21], and erlotinib [22,23] in epithelial ovarian cancer patients have shown only modest clinical responsiveness. The modest responses of EGFR blockade in response to the administration of monoclonal antibodies or tyrosine kinase inhibitors as single agents could be attributed to compensation through other signaling pathways.

It has been reported that different mechanisms might be involved in the crosstalk between GPCRs and EGFR [24]. Several GPCR ligands have been shown to activate the EGFR pathway contributing to carcinogenesis. PGE2 has been reported to activate the EGFR in hepatocarcinoma [25]. EGFR activation in response to GPCR ligands, including lysophosphatidic acid (LPA), has been reported in HNSCC cells [26]. Thus, the combined inhibition of EGFR and GPCR might enhance antitumor effects compared with single agents targeting EGFR alone. In our previous studies, we demonstrated PAFR gene and protein overexpression in ovarian cancer tissues and a series of ovarian cancer cell lines [27]. Phospho-antibody microarray analysis revealed increased EGFR, Src, FAK and Paxillin phosphorylation through PAF in OVCA429 and OVCA432 cells. We also showed that the combined PAFR and EGFR targeting synergistically inhibited the ovarian cancer in vitro and in vivo [28]. However, the mechanisms underlying EGFR phosphorylation through PAF/PAFR in human ovarian cancer have not yet been tested.

In the present study, we examined the SKOV-3, a well-characterized human serous ovarian cancer cell line with high levels of endogenous functional PAF-receptor expression, to characterize the interaction between the pathways mediated through PAFR and EGFR. The aim of this study was to determine whether PAF transactivates EGFR in ovarian cancer cells, examine the involvement of the PAFR in this process, and elucidate the intracellular signaling mechanisms required for transactivation. Activating growth factor receptors through PAF might be an important mechanism in mediating the downstream mitogenic effects of PAFR. This transactivation might reveal previously unknown associations between inflammatory and growth factor signaling, providing a better understanding of the relationship between inflammation and cancer.

\section{Materials and methods}

\section{Cell culture and chemical reagents}

The ovarian cancer cell lines SKOV-3, CAOV-3, OVC A433, RMUG-L and ES-2 (obtained from the Cell Bank of the Chinese Academy of Science, Shanghai, China) were maintained at $37^{\circ} \mathrm{C}$ in a humidified $5 \% \mathrm{CO}_{2}$ atmosphere in RPMI-1640 medium supplemented with $10 \%$ fetal calf serum (Gibco, Invitrogen, Carlsbad, CA), $100 \mathrm{IU} / \mathrm{ml}$ penicillin G, and $100 \mathrm{mg} / \mathrm{ml}$ streptomycin sulfate (SigmaAldrich, St. Louis, MO). The cells were serum starved through incubation in serum-free medium for 12-24 hours before the start of the experiments. $\beta$-Acetyl- $\gamma$-Oalkyl-L- $\alpha$-phosphatidylcholine (PAF), epidermal growth factor (EGF), WEB2086 (PAFR antagonist), AG1478 (EGFR inhibitor) and PP2 (Src inhibitor) were obtained from Sigma-Aldrich (St. Louis, MO). U73122 (PLC inhibitor), BAPTA-AM (calcium chelator), Thapsigargin $\left(\mathrm{Ca}^{2+}\right.$-ATPase inhibitor), GF109203X (PKC inhibitor), and PMA (PKC activator) were obtained from Tocris (Bristol, UK). The rabbit polyclonal antibodies used in this study were directed against phospho/total-EGFR, phospho/total-ERK, and phospho/total-Src. All antibodies were purchased from Cell Signaling Technology (Boston, MA). The mouse monoclonal antibodies used in this study were directed against actin (Sigma, Missouri, USA).

\section{Western blot analysis}

Cellular extracts were prepared in modified radioimmuno-

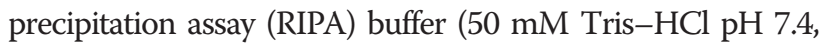
1\% NP-40, 0.25\% Na-deoxycholate, $150 \mathrm{mM} \mathrm{NaCl}, 1 \mathrm{mM}$ EDTA, $1 \mathrm{mM}$ PMSF, and protease inhibitor cocktail). The protein concentrations in the cellular extracts were measured using a Bio-Rad protein assay kit. The cellular extracts were subjected to SDS-PAGE, and the proteins were transferred onto PVDF membranes. After blocking for $1 \mathrm{~h}$ at room temperature in 5\% BSA, the blots were incubated with the primary antibody at a 1:1000 dilution and incubated overnight at $4^{\circ} \mathrm{C}$. Subsequently, the blots were washed three times and incubated for $1 \mathrm{~h}$ at room temperature with a 1:10000 dilution of secondary peroxidase-conjugated antibodies. After washing three times, the immunoreactive bands were detected using electrochemiluminescence (ECL).

\section{Quantitative real-time PCR}

Total RNA was extracted using Trizol reagent (TaKaRa, Japan) and reverse transcribed using the PrimeScript 
RT-PCR kit (TaKaRa, Japan) according to the manufacturer's instructions. Real-time PCR analyses were performed using SYBR Premix Ex Taq (TaKaRa, Japan) on a 7300 Real-time PCR system (Applied Biosystems, Inc. USA) at the recommended thermal cycling settings: one initial cycle at $95^{\circ} \mathrm{C}$ for $10 \mathrm{~s}$, followed by 40 cycles at $95^{\circ} \mathrm{C}$ for $5 \mathrm{~s}$ and $60^{\circ} \mathrm{C}$ for $31 \mathrm{~s}$. The following primer sequences were used for PAFR detection: sense, $5^{\prime}$ - GG GGACCCCCATCTGCCTCA -3' and antisense, 5'- GC GGGCAAAGACCCACAGCA -3'. The expression levels were normalized to the internal reference gene $18 \mathrm{~S}$ rRNA (sense, 5' - GTAACCCGTTGAACCCCATT -3' and antisense, $5^{\prime}$ - CCATCAATCGGTAGTAGCG -3') [29].

\section{Intracellular calcium measurement}

Calcium mobilization was performed as described previously [30]. The SKOV3 cells were harvested with Cell Stripper (Mediatech, Herndon, VA, USA), washed twice with PBS and resuspended to $5 \times 106$ cells $/ \mathrm{ml}$ in Hank's balanced salt solution $(140 \mathrm{mM} \mathrm{NaCl}, 5 \mathrm{mM} \mathrm{KCI}, 10 \mathrm{mM}$ HEPES, pH7.4, $1 \mathrm{mM} \mathrm{CaCl} 2,1 \mathrm{mM} \mathrm{MgCl}_{2}, 1 \mathrm{mg} / \mathrm{ml}$ glucose) containing $0.025 \%$ BSA. Subsequently, the cells were loaded with $3 \mu \mathrm{M}$ Fura-2 acetoxymethyl ester derivative (Fura-2/AM) (Molecular Probes, Eugene, OR, USA) for $30 \mathrm{~min}$ at $37^{\circ} \mathrm{C}$. The cells were washed once in Hank's solution, and then resuspended in Hank's at a concentration of $3 \times 10^{7}$ cells $/ \mathrm{ml}$. These cells were subsequently stimulated with $100 \mathrm{nM}$ PAF. The calcium flux was measured using excitation at 340 and $380 \mathrm{~nm}$ in a Tecan Infinite 200 pro series Microplate Reader (Tecan, Switzerland). When required, the cells were treated with WEB2086 for 1 hour in serum-free McCoy's $5 \mathrm{~A}$ medium prior to the experiment.

\section{HB-EGF assay}

Aliquots of the supernatant from stimulated ovarian cancer cells were collected and the HB-EGF concentrations were measured using a specific enzyme immunoassay kit (Cayman Chemical, Ann Arbor, MI). The assay was performed according to the manufacturer's instructions. HB-EGF production was evaluated in duplicates, and the concentrations were determined from a standard curve of HB-EGF. The sensitivity of the assay facilitated detection of up to $15 \mathrm{pg} / \mathrm{ml}$. When necessary, the samples were diluted in the assay buffer.

\section{Immunocytochemistry}

Following drug treatment, the cells were fixed with $100 \%$ methanol for $6 \mathrm{~min}$ at $-20^{\circ} \mathrm{C}$, washed with PBS and stored at $4^{\circ} \mathrm{C}$ until further use. The cells were permeabilized through incubation in PBS containing 0.3\% Triton X-100 and $5 \%$ goat serum for $30 \mathrm{~min}$. A polyclonal antibody against phospho-EGFR was used at a 1:100 dilution, and a secondary antibody FITC-conjugated goat anti- rabbit (Invitrogen, Carlsbad, CA), was used at a 1:200 dilution. The first antibody was incubated overnight at $4^{\circ} \mathrm{C}$ and the second antibody was incubated for 2 hours at RT. The images were captured using an Olympus DP 71 camera (Tokyo, Japan) at $400 \times$ magnification.

\section{Statistical analysis}

All experiments were performed at least three times. The data are expressed as the means $\pm \mathrm{SD}$. Wherever appropriate, the data were also subjected to unpaired, two-tailed Student's t-tests. The differences were considered significant at $P<0.05$.

\section{Results}

PAF increases EGFR phosphorylation in SKOV-3 cells

To determine the effects of PAF on EGFR transactivation in ovarian cancer cells, we used SKOV-3 for further investigations. In SKOV-3 cells, stimulation with PAF (100 nM) evoked EGFR phosphorylation in a time-dependent manner, with maximal activation at $5 \mathrm{~min}$ and a subsequent reduction to baseline after $25 \mathrm{~min}$ (Figure 1A). In addition, increasing concentrations of PAF increased EGFR phosphorylation in a dose-dependent manner, reaching maximum levels at $100 \mathrm{nM}$ (Figure 1B). Furthermore, the phosphorylation of EGFR through PAF was inhibited using AG1478 $(20 \mu \mathrm{M})$ (Figure 1C), a specific EGFR inhibitor [31], providing further support for the induction of EGFR transactivation through PAF in SKOV-3 cells.

\section{PAF-induced EGFR transactivation is dependent on the PAF-receptor}

We next investigated whether the PAF-receptor (PAFR) is involved in the transactivation of EGFR in ovarian cancer cells. Western blotting and reverse-transcription polymerase chain reaction were used to examine five ovarian cancer cell lines. As shown in Figure 2A and B, PAFR expression was higher in SKOV-3, CAOV-3 and OVCA433 cell lines, whereas PAFR expression was almost absent in RMUG-L cells. The results were consistent with those obtained in our previous study. We therefore chose SKOV-3 and RMUG-L cells for use in additional experiments. The staining intensity of phosphorylated EGFR, following $10 \mathrm{~min}$ of $100 \mathrm{nM}$ PAF treatment, was much higher in SKOV-3 cells than in control cells, while there was no obvious change between the PAF treatment group and the control group in RMUG-L cells (Figure 2C and D). Furthermore, in SKOV-3 cells, the activation of EGFR through PAF was inhibited with increasing concentrations of WEB2086 [32], a specific small-molecular inhibitor of PAFR (Figure 2E). These data indicate the PAFR is required for EGFR transactivation in ovarian cancer cells. 

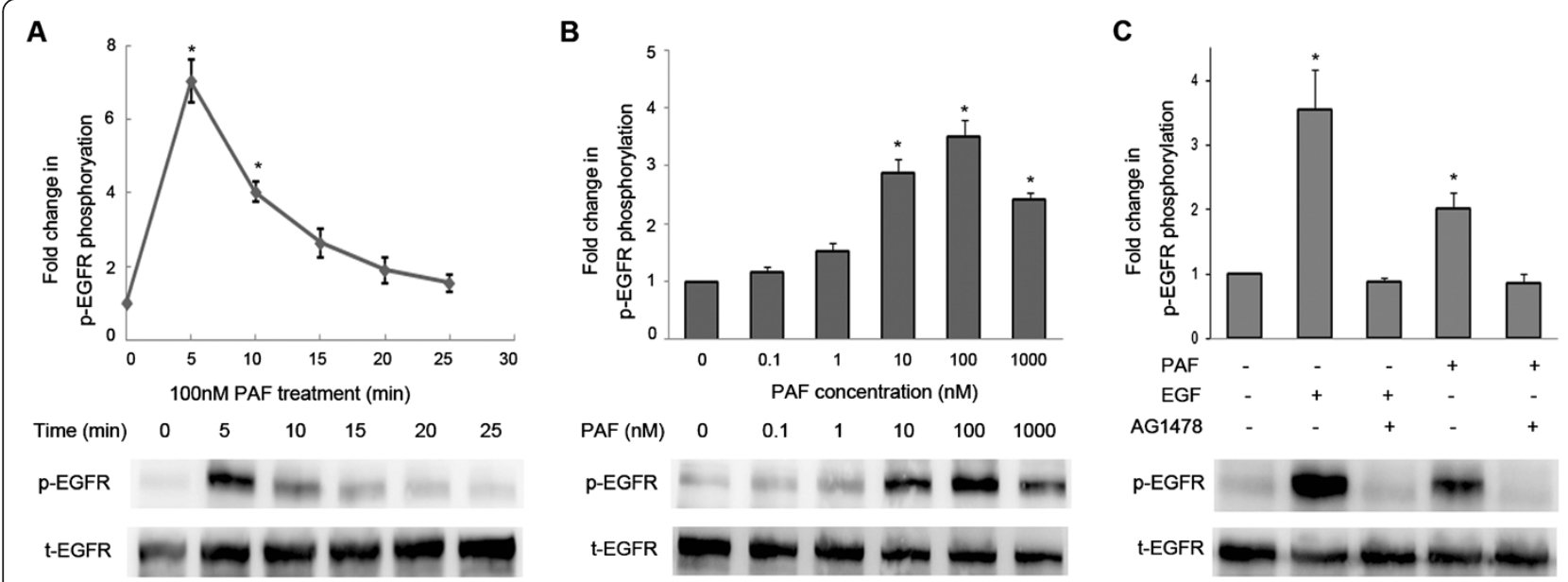

Figure 1 Effects of platelet-activating factor (PAF) on epidermal growth factor receptor (EGFR) activation in SKOV-3 cells. (A) SKOV-3 cells were treated with $100 \mathrm{nM}$ PAF for 0, 5, 10, 15, 20, or 25 min. Following PAF treatment, the cells were lysed, and the lysates were evaluated by Western blotting. Data were normalized to total EGFR protein expression and are expressed as fold-change (average \pm S.E.M.) in phospho-EGFR compared with vehicle-treated cells. Representative blots for phosphor/total-EGFR are shown. (B) SKOV-3 cells were treated with vehicle (0) or 0.1 to $1000 \mathrm{nM}$ PAF for $5 \mathrm{~min}$. Fold-phosphorylation data for immunoreactivity with antibodies against p-EGFR are shown in representative Western blots. (C) SKOV-3 cells were treated with AG1478 $(20 \mu \mathrm{M})$ for 1 hour before stimulation with PAF $(100 \mathrm{nM})$ or EGF (5 ng/ml) for $5 \mathrm{~min}$. Cells were harvested and subjected to Western blotting. The data shown are representative of at least three independent experiments. Data were analyzed using Student's t-test. * $p<0.05$.

\section{PAF activates ERK1/2 phosphorylation via both EGFR-dependent and EGFR-independent pathways}

ERK1/2 are kinases that promote survival and proliferation [33], and we have previously shown that ERK1/2 can be acutely activated through PAF and EGF receptor signaling pathways. Next, we examined the role of EGFR in the PAF-mediated activation of ERK1/2. As shown in Figure 3A, SKOV-3 cells were exposed with PAF (100 nM), and the stimulation evoked ERK1/2 phosphorylation in a time-dependent manner, with maximal activation at $5 \mathrm{~min}$ and a subsequent reduction to baseline after $20 \mathrm{~min}$. We pretreated serum-starved SKOV-3 cells with the EGFRspecific small-molecule inhibitor AG1478 $(20 \mu \mathrm{M})$, and the results showed that AG1478 only slightly inhibited the PAF-induced phosphorylation of ERK1/2 (Figure 3B). In addition, as shown in Figure $3 \mathrm{C}$, increasing concentrations of AG1478 did not effectively inhibit the PAF-induced ERK1/2 activation. These results indicate that ERK1/2 might be phosphorylated through PAF via EGFRdependent and EGFR-independent mechanisms in ovarian cancer cells.

\section{Involvement of calcium, but not PKC, in the PAF-induced transactivation of EGFR}

The available evidence indicates that G-protein coupled receptors (GPCR) mediate the activation of phospholipase $\mathrm{C}-\beta$ (PLC $\beta$ ) leading to the formation of inositol trisphosphate $\left(\mathrm{Ins}_{3}\right)$ and diacylglycerol (DAG) [34]. DAG directly activates classical types of PKCs, and IP3 activates intracellular $\mathrm{Ca}^{2+}[35]$. Therefore, we then examined the potential involvement of PLC $\beta$ in the transactivation of EGFR using the PLC inhibitor U73122 $(20 \mu \mathrm{M})$. SKOV-3 cancer cells were pretreated with $20 \mu \mathrm{M}$ of U73122 for 1 hour, followed by PAF or EGF stimulation for $5 \mathrm{~min}$. When cells were treated with PAF, U73122 significantly inhibited EGFR activation, while after treatment with EGF, U73122 only slightly affected EGFR activation (Figure 4A).

We next tried to determine which pathways downstream of PLC $\beta$ mediate the PAF-induced transactivation of EGFR. We observed the effects of the intracellular calcium chelator BAPTA-AM and thapsigargin, which increases intracellular calcium levels through the inhibition of the sarco/endoplasmic reticulum $\mathrm{Ca}^{2+}$-ATPase' (SERCA) pump, on the PAF-induced phosphorylation of EGFR in SKOV-3 cells. The cells were pretreated with BAPTA-AM for 1 hour prior to PAF or thapsigargin stimulation for $5 \mathrm{~min}$. As shown in Figure 4B, PAF and thapsigargin induced EGFR phosphorylation, while BAPTA-AM abrogated EGFR activation. Furthermore, we measured the effects of PAF and the PAF-receptor antagonist WEB2086 on intracellular calcium mobilization. As shown in Figure $4 \mathrm{C}$ and D, stimulation with PAF $(100 \mathrm{nM})$ elicited a rapid increase in intracellular $\mathrm{Ca}^{2+}$ mobilization in SKOV-3 cells, and the PAF-induced $\mathrm{Ca}^{2+}$ mobilization could be inhibited through pretreatment with WEB2086 for 1 hour.

To determine whether $\mathrm{PKC}$ is a downstream pathways of PLC $\beta$ involving in EGFR transactivation mediated through PAF, SKOV-3 cells were pretreated with $20 \mu \mathrm{M}$ of the PKC inhibitor GF109203X for 1 hour, followed by 


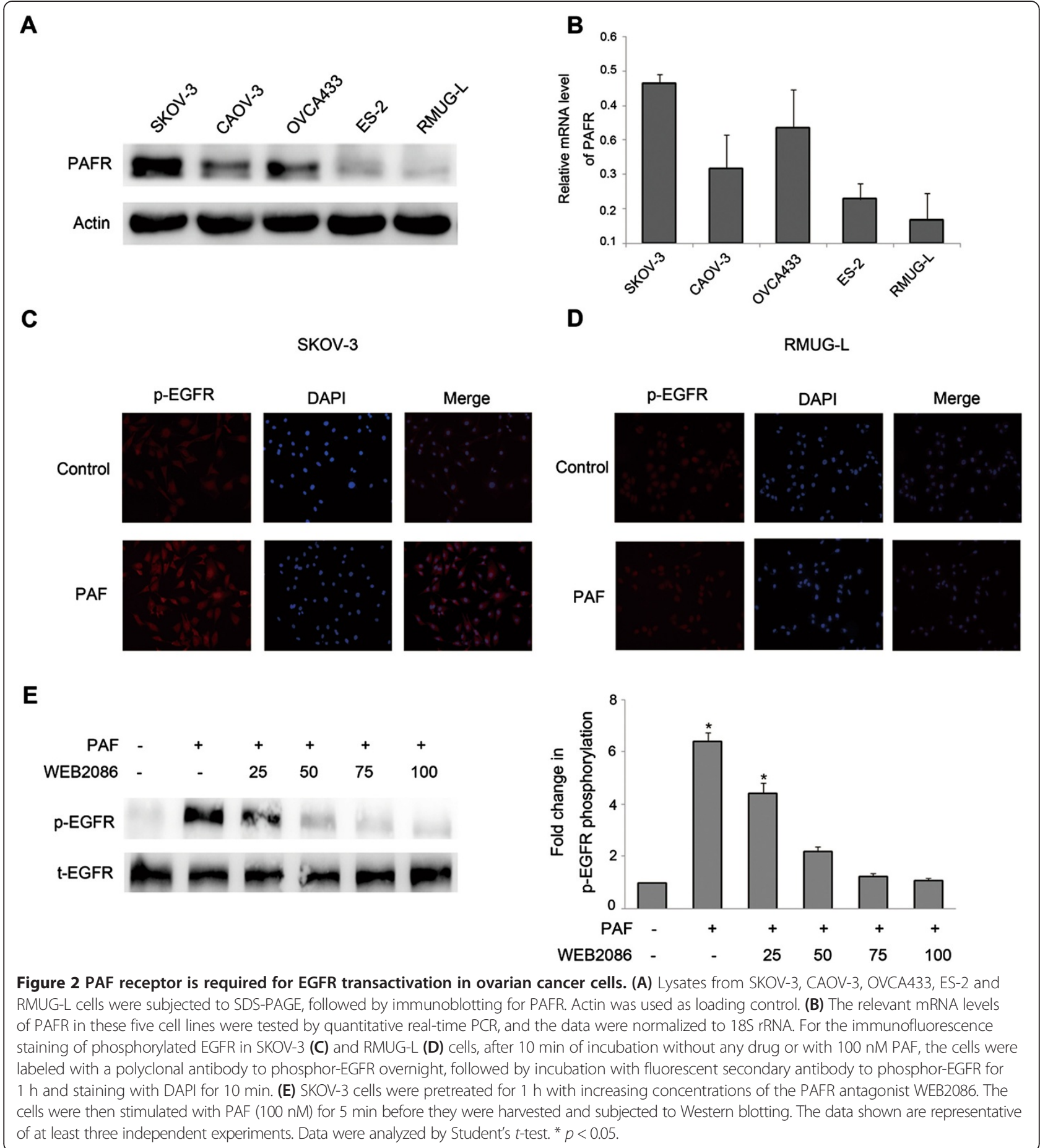

treatment with PAF or PMA, a PKC activator, for $5 \mathrm{~min}$. As shown in Figure 4E, little EGFR inhibition was observed when SKOV-3 cells were treated with GF109203X; however, treatment with GF109203X resulted in dramatic decreases in ERK1/2 activation followed by stimulation with PAF or PMA (Figure 4F). These results suggest that $\mathrm{Ca}^{2+}$, rather than PKC, mediated the PAF-induced transactivation of the EGFR via PLC $\beta$ activation.
Role of Src and metalloproteinases in the transactivation of EGFR

To further elucidate the mechanisms underlying the induction of EGFR transactivation through PAF, we investigated the role of Src kinases. In SKOV-3 cells, PAF stimulation led to the activation of Src kinases in a timedependent manner, with maximal activation at $5 \mathrm{~min}$ and a subsequent reduction to baseline after $25 \mathrm{~min}$ 

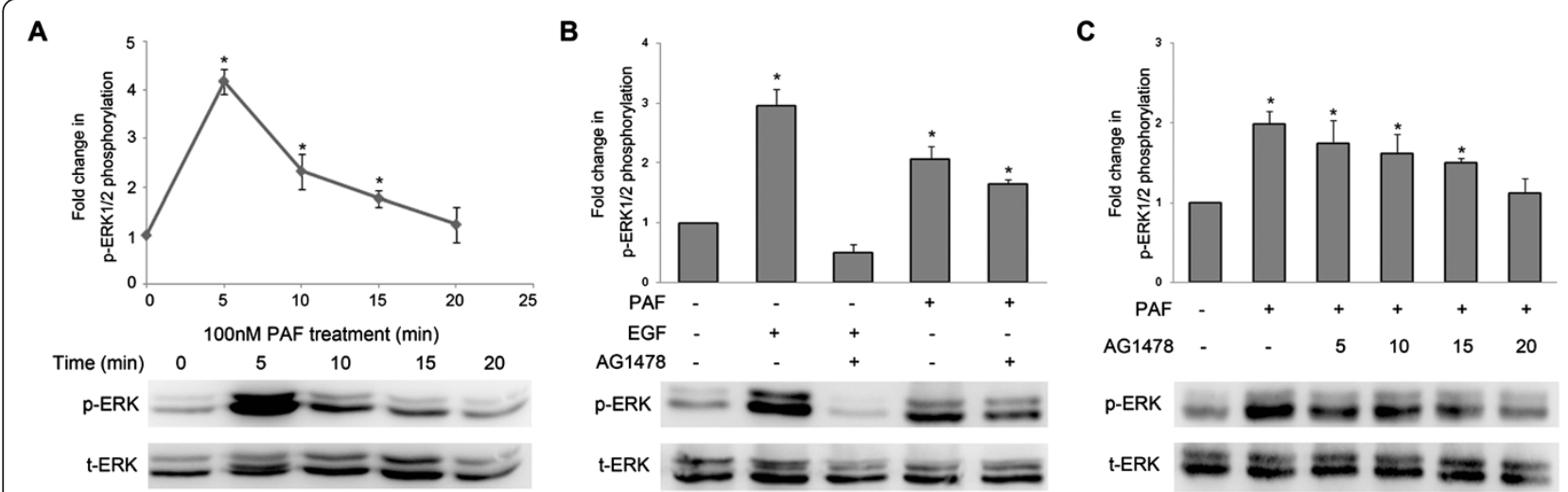

Figure 3 PAF activates ERK1/2 signaling via both EGFR-dependent and EGFR-independent pathways. (A) SKOV-3 cells were treated with $100 \mathrm{nM}$ PAF for 0, 5, 10, 15, or 20 min. Following PAF treatment, the cells were lysed, and the lysates were evaluated by Western blotting. Data were normalized to total ERK protein expression and are expressed as fold-change (average \pm S.E.M.) in phospho-ERK compared to vehicle-treated cells. Representative blots for phosphor/total-ERK are shown. (B) SKOV-3 cells were treated with AG1478 $(20 \mu \mathrm{M})$ for 1 hour before stimulation with PAF (100 nM) or EGF $(5 \mathrm{ng} / \mathrm{ml})$ for $5 \mathrm{~min}$. Cells were harvested and subjected to Western blot. (C) SKOV-3 cells were pretreated for $1 \mathrm{~h}$ with increasing concentrations of the EGFR inhibitor AG1478. Cells were then stimulated with PAF (100 nM) for 5 min before they were harvested and subjected to Western blot. The data shown are representative of at least three independent experiments. Data were analyzed by Student's t-test. ${ }^{*} p<0.05$.

(Figure 5A). As shown in Figure 5B, pretreatment with the Src inhibitor PP2 $(20 \mu \mathrm{M})$ abolished the PAFinduced phosphorylation of EGFR, but, had little effect on the phosphorylation of EGFR elicited through EGF. These results suggest the involvement of a Src family kinase in the PAF-induced transactivation of EGFR in SKOV-3 cells.

Previous evidence has implicated proteinases of the Adisintegrin-and metalloproteinase (ADAM) family in EGFR transactivation through GPCRs in various cells [36]. To examine the role of ADAMs in PAF-induced EGFR transactivation in SKOV-3 cells, we pretreated the cells with GM6001, a broad-spectrum metalloproteinase inhibitor. As shown in Figure $5 \mathrm{C}$, this pretreatment resulted in the inhibition of PAF-induced EGFR phosphorylation, while the EGF-induced phosphorylation of these proteins was not affected. In addition, we pretreated cells with increasing concentrations of GM6001 and observed that GM6001 inhibited the EGFR phosphorylation in a dosedependent manner (Figure 5D). These results indicate that transactivation is dependent on mechanisms involving the ADAM-mediated release of EGFR ligands.

\section{PAF-induced EGFR transactivation occurs via MMP- mediated release of $\mathrm{HB}-\mathrm{EGF}$}

EGFR can be activated through several ligands. EGFR ligands bind to the extracellular domain of EGFR, triggering signaling downstream cascades, including MAPK [37-39]. As shown in Figure 6A, SKOV-3 cells were pretreated with the HB-EGF neutralizing antibody for 1 hour, followed by PAF or EGF stimulation for $5 \mathrm{~min}$, and this treatment inhibited PAF-induced EGFR phosphorylation, while the EGF-induced phosphorylation of these proteins was hardly affected. As shown in Figure 6B, in SKOV-3 cells, HB-EGF production increased after $30 \mathrm{~min}$ of stimulation with PAF (100 nM) and continued to increase, reaching a maximum after 2 hours. Longer PAF stimulation caused no significant additional increase in HB-EGF release over that obtained at 2 hours. In addition, we examined the effects of the metalloproteinase inhibitor GM6001 on HB-EGF production in SKOV-3 cells. The cells were pretreated with GM6001 and the HB-EGF neutralizing antibody for 1 hour prior to PAF stimulation for 2 hours. Using an enzyme-linked immunosorbent assay, we analyzed HB-EGF production in the medium of SKOV-3 cells. HB-EGF levels increased in the medium after PAF stimulation and GM6001 treatment inhibited PAF-induced HB-EGF production (Figure 6C). These results indicated that the ADAM-mediated release of HB-EGF is involved in the PAF-induced transactivation of EGFR.

\section{Discussion}

In the present study, we demonstrated that PAFR is capable of stimulating the activation of EGFR and ERK1/2 in ovarian cancer cells endogenously expressing PAFR. PAFR-mediated ERK1/2 activation appeared to be secondary to EGFR stimulation, as the EGFR tyrosine kinase inhibitor AG1478 blocked PAF-induced ERK1/2 activation. However, the ERK1/2 activation induced through PAF is not entirely dependent on EGFR stimulation. As illustrated in the proposed model (Figure 7), the transactivation of the EGFR through PAF involves the PAFR, the activation of PLC $\beta$ with downstream signaling through $\mathrm{Ca}^{2+}$ mobilization, the tyrosine-protein kinase Src, matrix metalloproteinase- dependent cleavage and the secretion 


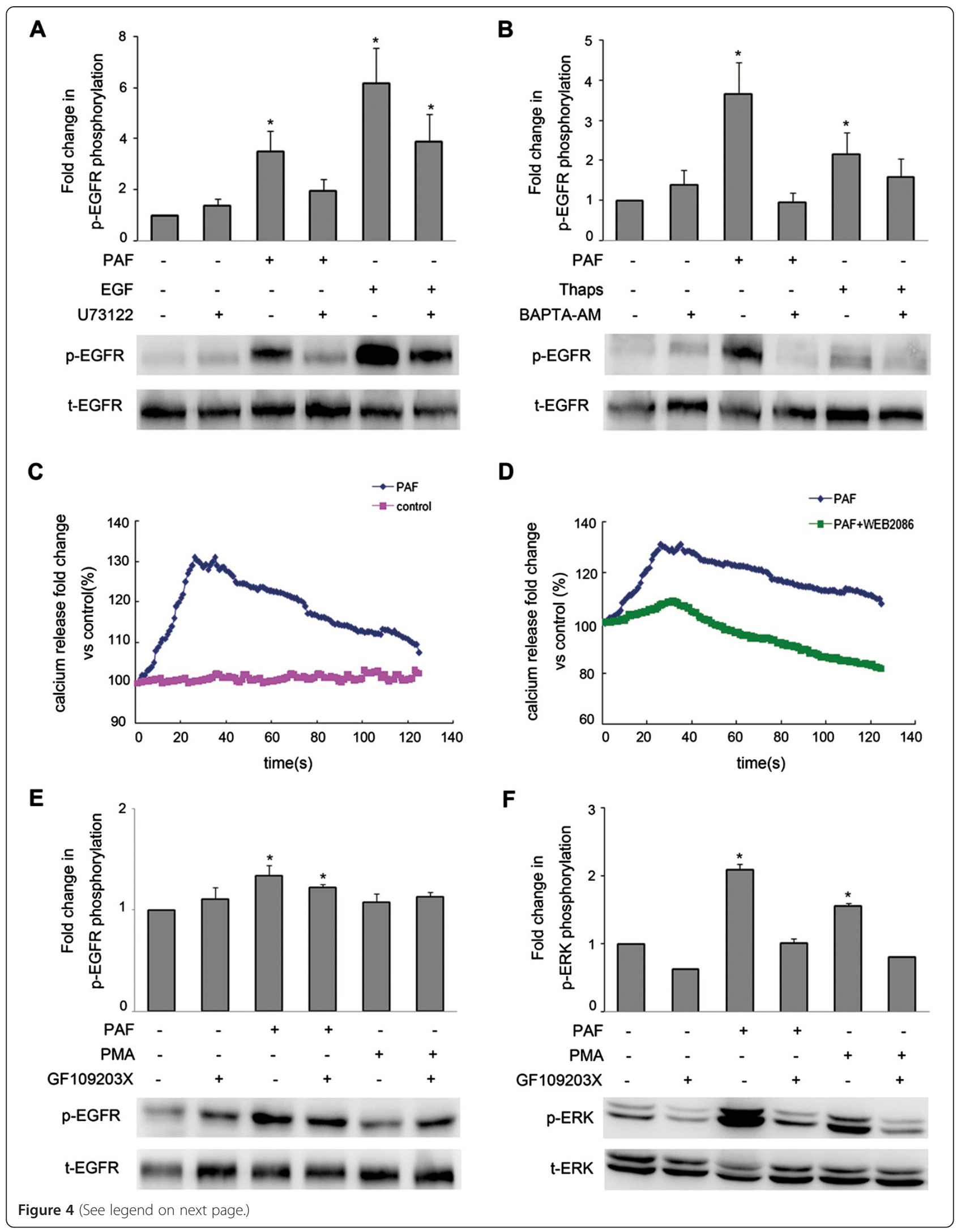


(See figure on previous page.)

Figure 4 Role of $\mathrm{Ca}^{2+}$ and PKC in responses to PAF in SKOV-3 cells. (A) SKOV-3 cells were pretreated for $1 \mathrm{~h}$ with the PLC $\beta$ inhibitor U73122 $(20 \mu \mathrm{M})$ before stimulation with PAF $(100 \mathrm{nM})$ or EGF $(5 \mathrm{ng} / \mathrm{ml})$ for $5 \mathrm{~min}$. (B) SKOV-3 cells were pretreated for $1 \mathrm{~h}$ with the Ca ${ }^{2+}$ chelator BAPTAAM $(20 \mu \mathrm{M})$ before stimulation with PAF (100 nM) or thapsigargin $(1 \mu \mathrm{M})$ for $5 \mathrm{~min}$. (C) SKOV-3 cells were loaded with the calcium probe Fura-2/ AM followed by stimulation with 100 nM PAF. (D) SKOV-3 cells were loaded with the calcium probe Fura-2/AM followed by stimulation with 100 nM PAF in the presence or absence of WEB2086, calcium mobilization was assayed by monitoring the change in Fura-2/AM fluorescence. (E and F) SKOV-3 cells were pretreated for $1 \mathrm{~h}$ with the PKC inhibitor GF109203X (5 $\mu \mathrm{M})$ before stimulation with PAF (100 nM) or PMA (1 $\mu \mathrm{M})$ for 5 min. Cells were then harvested and subjected to Western blot analysis. The data shown are representative of at least three independent experiments. Data were analyzed by Student's t-test. * $p<0.05$.

of HB-EGF which activates the EGFR and subsequently phosphorylates ERK1/2. The transactivation of EGFR through other G-protein coupled receptors (GPCR) is an important signaling pathway for the induction of both mitogenic and motogenic effects, suggesting a mechanism for the proliferative effects of PAF in ovarian cancer cells.
As a member of G-protein coupled receptors, PAFR is involved in many biological functions, including inflammation, cell growth, chemotaxis and oncogenesis. Several recent reports provide evidences linking inflammation and cancer promotion [40,41]. Inflammatory moleculars, such as PAF and LPA, in the tumor
A

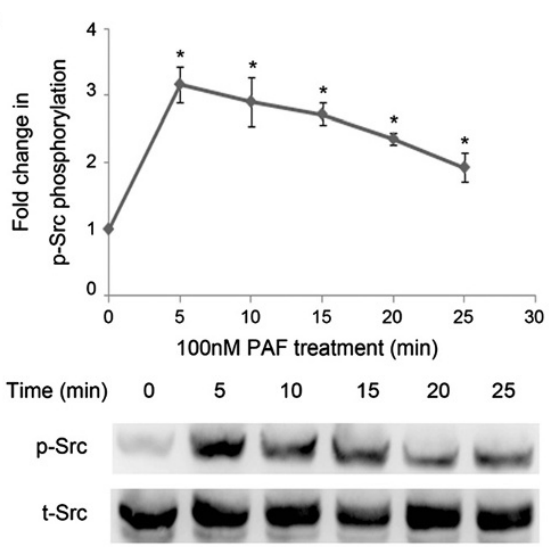

C

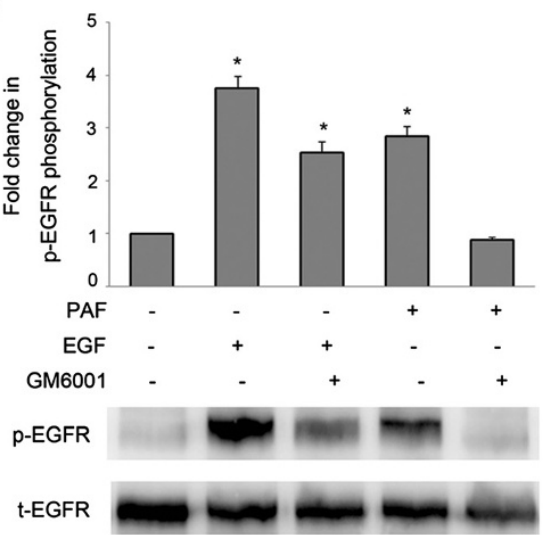

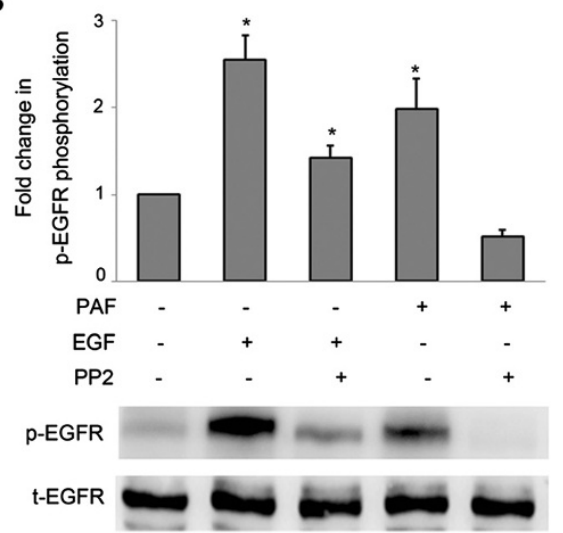

D

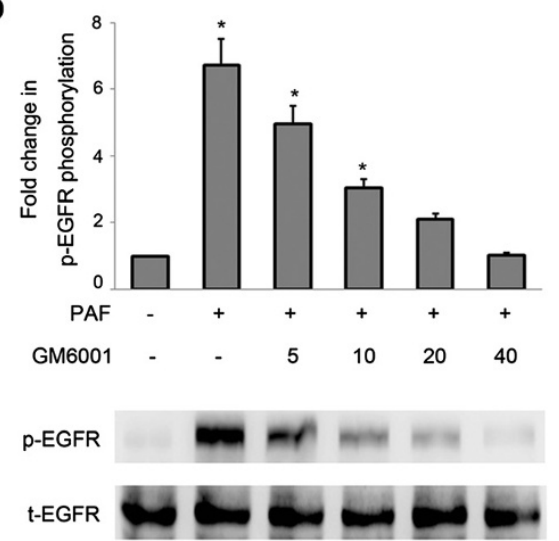

Figure 5 Effect of Src and MMP inhibitors on EGFR phosphorylation. (A) SKOV-3 cells were treated with 100 nM PAF for 0, 5, 10, 15, 20, or $25 \mathrm{~min}$. Following PAF treatment, cells were lysed and lysates were evaluated by Western blotting. Data were normalized to total Src protein expression and are expressed as the fold change (average \pm S.E.M.) in phospho-Src compared to vehicle-treated cells. Representative blots for phosphor/total-EGFR are shown. (B) SKOV-3 cells were treated with the Src inhibitor PP2 (20 $\mu \mathrm{M})$ for 1 hour before stimulation with PAF (100 nM) or EGF $(5 \mathrm{ng} / \mathrm{ml}$ ) for $5 \mathrm{~min}$. Cells were harvested and subjected to Western blot. (C) SKOV-3 cells were pretreated for $1 \mathrm{~h}$ with the metalloproteinase inhibitor GM6001 (20 $\mu \mathrm{M})$. Cells were then stimulated with either PAF (100 nM) or EGF $(5 \mathrm{ng} / \mathrm{ml})$ for 5 min before they were harvested and immunoblotting. (D) SKOV-3 cells were pretreated for $1 \mathrm{~h}$ with increasing concentrations of the metalloproteinase inhibitor GM6001 before they were harvested and subjected to Western blot. The data shown are representative of at least three independent experiments. Data were analyzed by Student's t-test. * $p<0.05$. 


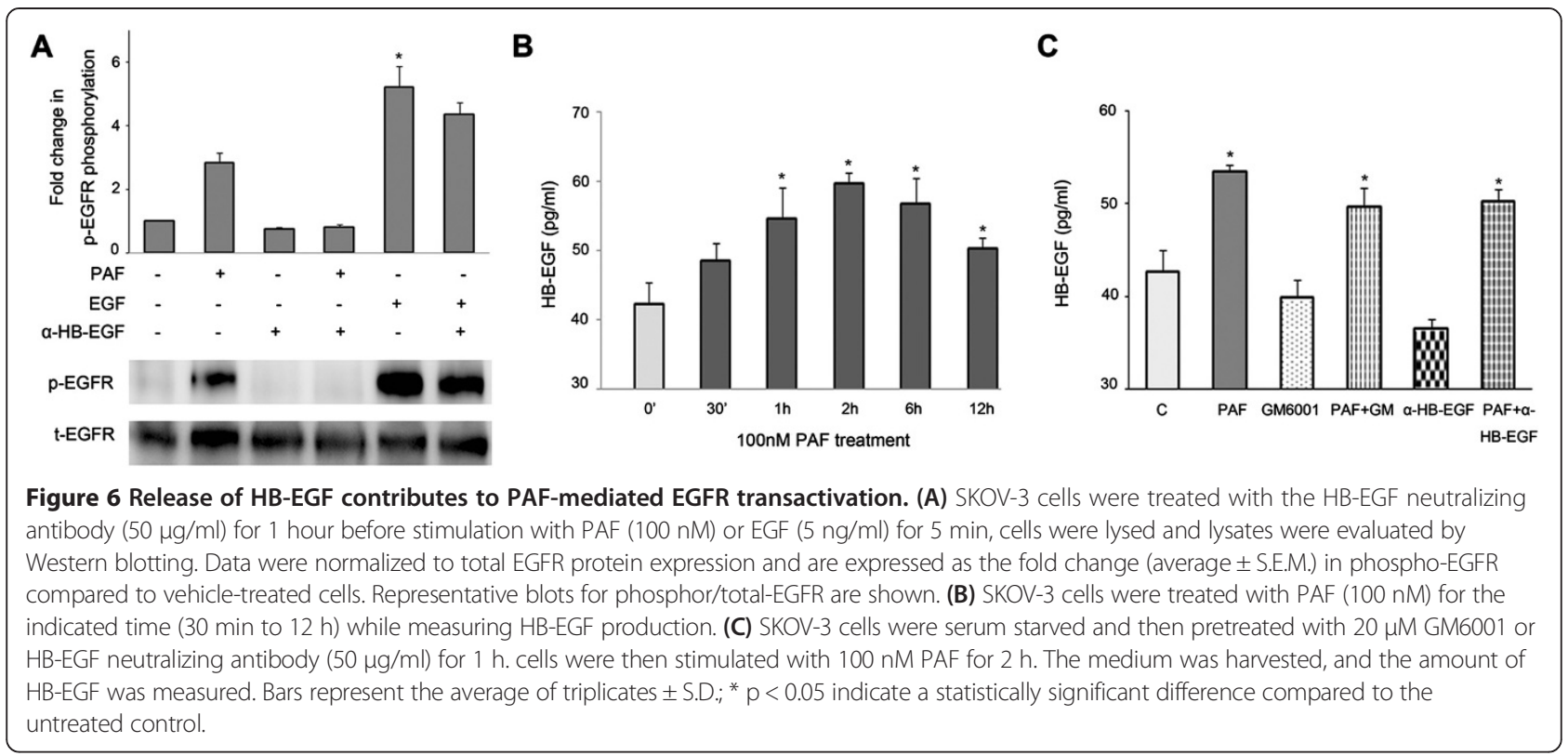

microenvironment bind GPCRs and induce mitogenesis and invasion in several cancers, including ovarian cancer $[42,43]$. The GPCR-mediated transactivation of EGFR leads to the downstream activation of ERK1/2. Depending on the cell type and the GPCR ligand, ERK1/2 might be activated via EGFR-dependent and/or EGFR-independent mechanisms [44,45]. In the present study, we observed that PAF-induced ERK1/2 phosphorylation can be inhibited with the EGFR tyrosine kinase inhibitor AG1478, but this inhibition was slightly. In addition, increasing concentrations of AG1478, did not lead to the obvious inhibition of ERK1/2 phosphorylation. These results suggest that there might be other mechanisms of PAF-induced ERK1/2 activation.
When G-protein coupled receptors were activated, downstream PLC $\beta$ could regulate cellular functions through two distinct pathways involving the DAGmediated activation of PKC and the InsP3-induced release and elevation of cytosolic $\mathrm{Ca}^{2+}$, respectively. Our findings suggest that in the SKOV-3 cells, PAF-induced EGFR transactivation was mediated through $\mathrm{Ca}^{2+}$, as the PKC activator PMA did not mimic this effect and the PKC blocker GF109203X did not inhibit this effect. However, thapsigargin, which elevates intracellular $\mathrm{Ca}^{2+}$, mimicked the PAF effect, and the $\mathrm{Ca}^{2+}$ chelator BAPTAAM blocked the transactivation of EGFR phosphorylation. However, the PKC activator PMA activated the phosphorylation of ERK, and the phosphorylation of ERK

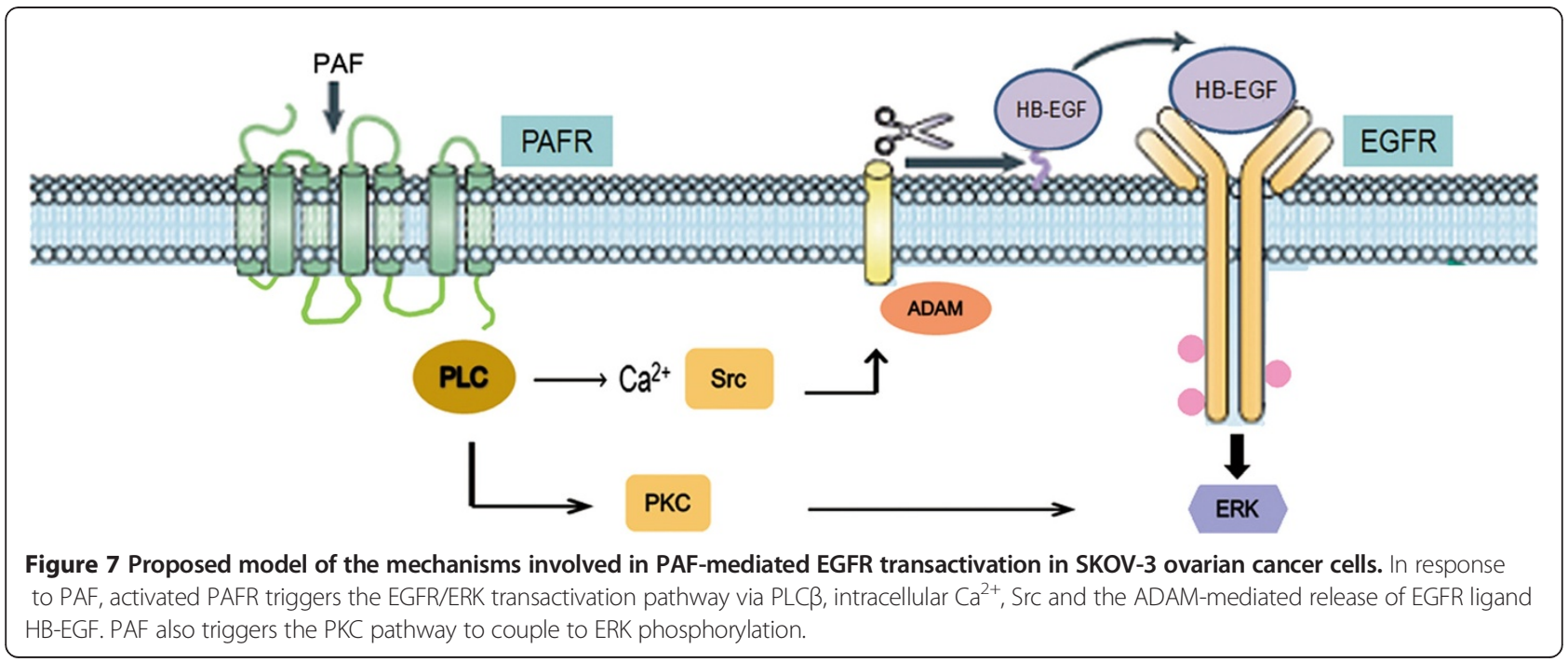


was inhibited by PKC inhibitor GF109203X, indicating that PAF activates ERK, the downstream target of EGFR, via PLC $\beta$-dependent PKC and MMP-mediated EGFR pathways to promote ovarian cancer progression.

In different types of cells, both ligand-dependent and ligand-independent mechanisms mediate EGFR transactivation [46]. Ligand-dependent mechanisms involve the release of EGFR agonists through the cleavage and shedding of membrane-associated precursors by proteinases of the ADAM family [47]. Ligand-independent mechanisms have been reported to involve intracellular molecules, including Src family kinases and Pyk2 [48,49]. In the SKOV-3 cells, we observed that Src inhibitors abolished the PAF-induced phosphorylation of the EGFR. In contrast, these inhibitors only slightly affected the response to EGF, suggesting a role for Src in the transactivation of EGFR in SKOV-3 cells. We also observed the involvement of HB-EGF shedding in the transactivation of EGFR after PAF stimulation, as pretreatment with the metalloproteinase inhibitor GM6001 almost completely prevented the PAF-induced, but not EGF-induced, phosphorylation of EGFR in these cells. HB-EGF is released after PAF treatment, and increased HB-EGF concentrations are blocked through the metalloproteinase inhibitor GM6001. These results indicate that in the SKOV-3 cells, Src is involved in the activation of ADAMs, rather than directly stimulating the EGFR, thus combining these two mechanisms.

EGFR is expressed at high levels in ovarian cancer, where signaling through EGFR contributes to cell survival, proliferation and invasion. The inhibition of EGFR alone, has resulted in limited antitumor effects when tested as a monotherapy in clinical trials. In addition to receptor tyrosine kinase, PAFR regulates the responsiveness of cancer cells to the ligand PAF. It has become increasingly evident that the crosstalk between PAFR and EGFR confer an aggressive tumorigenic phenotype in cancer cells. In the present study, we have shown that the activation of both PAFR and EGFR induces the phosphorylation of the MAPK pathway, and PAF mediates the transactivation of EGFR. Indeed, combined treatment with an EGFR tyrosine kinase inhibitor and the PAFR antagonist resulted in additive antitumor effects. We have shown that PAF stimulates ERK1/2 through different mechanisms, acting by PAFR-mediated EGFR transactivation in ovarian cancer cells. This evidence further confirms the diversity of intracellular crosstalk and underscores the importance of investigating these mechanisms to better understand signaling in cancer cells.

\section{Conclusions}

In the present study, we demonstrated that PAF transactivates EGFR through PAFR in both time- and dosedependent manners in the SKOV-3 ovarian cancer cells.
EGFR transactivation was dependent on the PAF-receptor, PLC $\beta, \mathrm{Ca}^{2+}$, Src and the ADAM-mediated release of HB-EGF. These results support the development of therapeutic strategies involving the combined EGFR and PAFR targeting in ovarian cancer.

\section{Abbreviations}

PAF: Platelet-activating factor; PAFR: PAF-receptor; EGF: Epidermal growth factor; EGFR: EGF-receptor; HB-EGF: Heparin-binding epidermal growth factor; GPCR: G-protein coupled receptor (GPCR) family; PLC $\beta$ : Phospholipase C- $\beta$; ERK: Extracellular-regulated protein kinase; InsP $P_{3}$ Inositol trisphosphat; DAG: Diacylglycerol; ADAM: A disintegrin and metalloproteinase; MMP: Metalloproteinase; AG1478: An EGFR-specific tyrosine kinase inhibitor; WEB2086: A specific PAFR antagonist.

\section{Competing interests}

The authors declare that they have no competing interests.

\section{Authors' contributions}

YY performed the experiments and drafted the manuscript. XYZ participated in the design of this study. MXZ and QQC participated in the experiments. ZLZ, WJ and CJX contributed to the design of this study, final data analysis and edited the manuscript. All authors read and approved the final manuscript.

\section{Authors' information}

Zhiling Zhu, Wei Jiang and Congjian Xu joint corresponding authors.

\section{Acknowledgements}

This work was financially supported through grants from the National Natural Sciences Foundation of China (81202052) awarded to WJ, and the Medical Pilot Project of the Shanghai Municipal Science and Technology Commission (114119a2300) awarded to WJ.

\section{Author details}

'Obstetrics and Gynecology Hospital, Fudan University, No.419 Fang-Xie Road, Shanghai 200011, People's Republic of China. ${ }^{2}$ Department of Obstetrics and Gynecology of Shanghai Medical School, Fudan University, No.138 Yi-Xueyuan Road, Shanghai 200032, People's Republic of China. ${ }^{3}$ Shanghai Key Laboratory of Female Reproductive Endocrine Related Diseases, No. 413 Zhao-Zhou Road, Shanghai 200011, People's Republic of China. ${ }^{4}$ Institute of Biomedical Sciences, Fudan University, Shanghai 200032, No.138 Yi-Xueyuan Road, Shanghai 200032, People's Republic of China.

Received: 22 July 2014 Accepted: 24 September 2014 Published online: 28 September 2014

\section{References}

1. Okubo M, Yamanaka H, Kobayashi K, Kanda H, Dai Y, Noguchi K: Up-regulation of platelet-activating factor synthases and its receptor in spinal cord contribute to development of neuropathic pain following peripheral nerve injury. Mol Pain 2012, 8:8.

2. Zhu T, Gobeil F, Vazquez-Tello A, Leduc M, Rihakova L, Bossolasco M, Bkaily G, Peri K, Varma DR, Orvoine R, Chemtob S: Intracrine signaling through lipid mediators and their cognate nuclear G-protein-coupled receptors: a paradigm based on PGE2, PAF, and LPA1 receptors. Can J Physiol Pharmacol 2006, 84:377-391.

3. Liu C, Liu H, Wang X, Xinbo S: Clinical significance and expression of PAF and TNF-alpha in seminal plasma of leukocytospermic patients. Mediators Inflamm 2012, 2012:639735.

4. Li S, Ma X, Ma L, Wang C, He Y, Yu Z: Effects of ectopic HER-2/neu gene expression on the COX-2/PGE2/P450arom signaling pathway in endometrial carcinoma cells: HER-2/neu gene expression in endometrial carcinoma cells. $J$ Exp Clin Cancer Res 2013, 32:11.

5. Li J, Guo B, Wang J, Cheng X, Xu Y, Sang J: Ovarian cancer G protein coupled receptor 1 suppresses cell migration of MCF7 breast cancer cells via a Galpha12/13-Rho-Rac1 pathway. J Mol Signal 2013, 8:6.

6. O'Hayre M, Vazquez-Prado J, Kufareva I, Stawiski EW, Handel TM, Seshagiri S, Gutkind JS: The emerging mutational landscape of $\mathrm{G}$ proteins and G-protein-coupled receptors in cancer. Nat Rev Cancer 2013, 13:412-424. 
7. Venkatakrishnan AJ, Deupi X, Lebon G, Tate CG, Schertler GF, Babu MM: Molecular signatures of G-protein-coupled receptors. Nature 2013, 494:185-194.

8. Zhang L, Wang D, Jiang W, Edwards D, Qiu W, Barroilhet LM, Rho JH, Jin L, Seethappan V, Vitonis A, Wang J, Mok SC, Cramer DW, Ye B: Activated networking of platelet activating factor receptor and FAK/STAT1 induces malignant potential in BRCA1-mutant at-risk ovarian epithelium. Reprod Biol Endocrinol 2010, 8:74

9. Kim HA, Kim KJ, Seo KH, Lee HK, Im SY: PTEN/MAPK pathways play a key role in platelet-activating factor-induced experimental pulmonary tumor metastasis. FEBS Lett 2012, 586:4296-4302

10. Kang NI, Yoon HY, Kim HA, Kim KJ, Han MK, Lee YR, Hwang PH, Soh BY, Shin SJ, Im SY, Lee HK: Protein kinase CK2/PTEN pathway plays a key role in platelet-activating factor-mediated murine anaphylactic shock. J Immunol 2011, 186:6625-6632

11. Borthakur A, Bhattacharyya S, Alrefai WA, Tobacman JK, Ramaswamy K, Dudeja PK: Platelet-activating factor-induced NF-kappaB activation and $\mathrm{IL}-8$ production in intestinal epithelial cells are $\mathrm{Bcl} 10$-dependent. Inflamm Bowel Dis 2010, 16:593-603.

12. Gui T, Shen K: The epidermal growth factor receptor as a therapeutic target in epithelial ovarian cancer. Cancer Epidemiol 2012, 36:490-496.

13. Marinas MC, Mogos G, Ciurea R, Mogos DG: EGFR, HER2/neu and Ki67 immunoexpression in serous ovarian tumors. Rom J Morphol Embryol 2012, 53:563-567.

14. Gottschalk N, Kimmig R, Lang S, Singh M, Brandau S: Anti-epidermal growth factor receptor (EGFR) antibodies overcome resistance of ovarian cancer cells to targeted therapy and natural cytotoxicity. Int J Mol Sci 2012, 13:12000-12016

15. Li D, Bi FF, Cao JM, Cao C, Li CY, Yang Q: Effect of BRCA1 on epidermal growth factor receptor in ovarian cancer. J Exp Clin Cancer Res 2013, 32:102.

16. del Carmen MG, Micha J, Small L, Street DG, Londhe A, McGowan T: A phase II clinical trial of pegylated liposomal doxorubicin and carboplatin plus bevacizumab in patients with platinum-sensitive recurrent ovarian, fallopian tube, or primary peritoneal cancer. Gynecol Oncol 2012, 126:369-374.

17. Secord AA, Blessing JA, Armstrong DK, Rodgers WH, Miner Z, Barnes MN, Lewandowski G, Mannel RS: Phase II trial of cetuximab and carboplatin in relapsed platinum-sensitive ovarian cancer and evaluation of epidermal growth factor receptor expression: a Gynecologic Oncology Group study. Gynecol Oncol 2008, 108:493-499.

18. Schilder RJ, Pathak HB, Lokshin AE, Holloway RW, Alvarez RD, Aghajanian C, Min H, Devarajan K, Ross E, Drescher CW, Godwin AK: Phase II trial of single agent cetuximab in patients with persistent or recurrent epithelial ovarian or primary peritoneal carcinoma with the potential for dose escalation to rash. Gynecol Oncol 2009, 113:21-27.

19. Palayekar MJ, Herzog TJ: The emerging role of epidermal growth factor receptor inhibitors in ovarian cancer. Int J Gynecol Cancer 2008, 18:879-890.

20. Seiden MV, Burris HA, Matulonis U, Hall JB, Armstrong DK, Speyer J, Weber JD, Muggia F: A phase II trial of EMD72000 (matuzumab), a humanized antiEGFR monoclonal antibody, in patients with platinum-resistant ovarian and primary peritoneal malignancies. Gynecol Oncol 2007, 104:727-731.

21. Pautier $P$, Joly F, Kerbrat $P$, Bougnoux $P$, Fumoleau $P$, Petit $T$, Rixe $O$, Ringeisen F, Carrasco AT, Lhomme C: Phase II study of gefitinib in combination with paclitaxel $(P)$ and carboplatin (C) as second-line therapy for ovarian, tubal or peritoneal adenocarcinoma (1839IL/0074). Gynecol Oncol 2010, 116:157-162.

22. Hirte HW: Profile of erlotinib and its potential in the treatment of advanced ovarian carcinoma. Onco Targets Ther 2013, 6:427-435.

23. Holmberg LA, Goff B, Veljovich D: Unexpected gastrointestinal toxicity from Docetaxel/Carboplatin/Erlotinib followed by maintenance Erlotinib treatment for newly diagnosed stage III/IV ovarian cancer, primary peritoneal, or fallopian tube cancer. Gynecol Oncol 2011, 121:426.

24. Muller KM, Tveteraas $\mathrm{H}$, Aasrum M, Odegard J, Dawood M, Dajani O, Christoffersen T, Sandnes DL: Role of protein kinase $C$ and epidermal growth factor receptor signalling in growth stimulation by neurotensin in colon carcinoma cells. BMC Cancer 2011, 11:421.

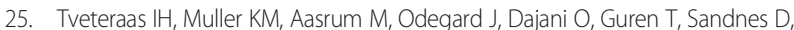
Christoffersen T: Mechanisms involved in PGE2-induced transactivation of the epidermal growth factor receptor in $\mathrm{MH} 1 \mathrm{C} 1$ hepatocarcinoma cells. J Exp Clin Cancer Res 2012, 31:72.

26. Matayoshi S, Chiba S, Lin Y, Arakaki K, Matsumoto H, Nakanishi T, Suzuki M, Kato S: Lysophosphatidic acid receptor 4 signaling potentially modulates malignant behavior in human head and neck squamous cell carcinoma cells. Int J Oncol 2013, 42:1560-1568.

27. Aponte M, Jiang W, Lakkis M, Li MJ, Edwards D, Albitar L, Vitonis A, Mok SC, Cramer DW, Ye B: Activation of platelet-activating factor receptor and pleiotropic effects on tyrosine phospho-EGFR/Src/FAK/paxillin in ovarian cancer. Cancer Res 2008, 68:5839-5848.

28. Yu Y, Zhang M, Zhang X, Cai Q, Hong S, Jiang W, Xu C: Synergistic effects of combined platelet-activating factor receptor and epidermal growth factor receptor targeting in ovarian cancer cells. J Hematol Oncol 2014, 7:39.

29. Schmittgen TD, Zakrajsek BA: Effect of experimental treatment on housekeeping gene expression: validation by real-time, quantitative RT-PCR. J Biochem Biophys Methods 2000, 46:69-81.

30. Li G, Shi Y, Huang H, Zhang Y, Wu K, Luo J, Sun Y, Lu J, Benovic JL, Zhou N: Internalization of the human nicotinic acid receptor GPR109A is regulated by G(i), GRK2, and arrestin3. J Biol Chem 2010, 285:22605-22618.

31. Yan $Y, A i Z$, Wang J, Xu $Y$, Teng $Y$ : Influence of epidermal growth factor receptor inhibitor AG1478 on epithelial-mesenchymal transition in endometrial carcinoma cells. Int J Gynecol Cancer 2012, 22:1457-1462.

32. Onuchic AC, Machado CM, Saito RF, Rios FJ, Jancar S, Chammas R: Expression of PAFR as part of a prosurvival response to chemotherapy: a novel target for combination therapy in melanoma. Mediators Inflamm 2012, 2012:175408.

33. Oak JN, Lavine N, Van Tol HH: Dopamine $\mathrm{D}(4)$ and $\mathrm{D}(2 \mathrm{~L})$ receptor stimulation of the mitogen-activated protein kinase pathway is dependent on trans-activation of the platelet-derived growth factor receptor. Mol Pharmacol 2001, 60:92-103.

34. Szumilo M, Rahden-Staron I: Phosphoinositide-specific phospholipase $C$ in mammalian cells: structure, properties, and function. Postepy Hig Med Dosw (Online) 2008, 62:47-54.

35. Sugawara $Y$, Echigo R, Kashima K, Minami H, Watanabe M, Nishikawa Y, Muranishi M, Yoneda M, Ohno-Shosaku T: Intracellular calcium level is an important factor influencing ion channel modulations by PLC-coupled metabotropic receptors in hippocampal neurons. Brain Res 2013, 1512:9-21.

36. Kasina S, Scherle PA, Hall CL, Macoska JA: ADAM-mediated amphiregulin shedding and EGFR transactivation. Cell Prolif 2009, 42:799-812.

37. Tanida S, Kataoka H, Mizoshita $T$, Shimura $T$, Kamiya $T$, Joh T: Intranuclear translocation signaling of HB-EGF carboxy-terminal fragment and mucosal defense through cell proliferation and migration in digestive tracts. Digestion 2010, 82:145-149.

38. Kerpedjieva SS, Kim DS, Barbeau DJ, Tamama K: EGFR ligands drive multipotential stromal cells to produce multiple growth factors and cytokines via early growth response-1. Stem Cells Dev 2012, 21:2541-2551.

39. Diaz B, Yuen A, lizuka S, Higashiyama S, Courtneidge SA: Notch increases the shedding of HB-EGF by ADAM12 to potentiate invadopodia formation in hypoxia. J Cell Biol 2013, 201:279-292.

40. Liao R, Sun J, Wu H, Yi Y, Wang JX, He HW, Cai XY, Zhou J, Cheng YF, Fan J, Qiu SJ: High expression of IL-17 and IL-17RE associate with poor prognosis of hepatocellular carcinoma. J Exp Clin Cancer Res 2013, 32:3.

41. Liao R, Wu H, Yi Y, Wang JX, Cai XY, He HW, Cheng YF, Zhou J, Fan J, Sun J, Qiu SJ: Clinical significance and gene expression study of human hepatic stellate cells in HBV related-hepatocellular carcinoma. J Exp Clin Cancer Res 2013, 32:22.

42. Jiang W, Wang YS, Cong Q, Li MJ, Ye B, Xu CJ: Effects and mechanisms of platelet-activating factor on the invasiveness of ovarian cancer cells in vitro. Zhonghua Fu Chan Ke Za Zhi 2011, 46:931-935.

43. Ha JH, Ward JD, Varadarajalu L, Kim SG, Dhanasekaran DN: The gep proto-oncogene Galpha12 mediates LPA-stimulated activation of CREB in ovarian cancer cells. Cell Signal 2014, 26:122-132.

44. Kruk JS, Vasefi MS, Liu H, Heikkila JJ, Beazely MA: 5-HT(1A) receptors transactivate the platelet-derived growth factor receptor type beta in neuronal cells. Cell Signal 2013, 25:133-143.

45. Chun KS, Lao HC, Langenbach R: The prostaglandin E2 receptor, EP2, stimulates keratinocyte proliferation in mouse skin by $\mathrm{G}$ protein-dependent and \{beta\}-arrestin1-dependent signaling pathways. J Biol Chem 2010, 285:39672-39681.

46. Zhang $X$, Diaz MR, Yee D: Fulvestrant regulates epidermal growth factor (EGF) family ligands to activate EGF receptor (EGFR) signaling in breast cancer cells. Breast Cancer Res Treat 2013, 139:351-360.

47. Ohtsu H, Dempsey PJ, Eguchi S: ADAMs as mediators of EGF receptor transactivation by $\mathrm{G}$ protein-coupled receptors. Am J Physiol Cell Physiol 2006, 291:C1-C10. 
48. Bai X, Wang J, Zhang L, Ma J, Zhang H, Xia S, Zhang M, Ma X, Guo Y, Rong R, Cheng S, Shu W, Wang Y, Leng J: Prostaglandin E(2) receptor EP1-mediated phosphorylation of focal adhesion kinase enhances cell adhesion and migration in hepatocellular carcinoma cells. Int J Oncol 2013, 42:1833-1841.

49. Block ER, Tolino MA, Klarlund JK: Extracellular ATP stimulates epithelial cell motility through Pyk2-mediated activation of the EGF receptor. Cell Signal 2011, 23:2051-2055.

doi:10.1186/s13046-014-0085-6

Cite this article as: Yu et al:: Transactivation of epidermal growth factor receptor through platelet-activating factor/receptor in ovarian cancer cells. Journal of Experimental \& Clinical Cancer Research 2014 33:85.

\section{Submit your next manuscript to BioMed Central and take full advantage of:}

- Convenient online submission

- Thorough peer review

- No space constraints or color figure charges

- Immediate publication on acceptance

- Inclusion in PubMed, CAS, Scopus and Google Scholar

- Research which is freely available for redistribution 